$831,7-829,9$ C.C. Gas, dessen procentische Zusammensetzung war $3,57 \mathrm{~N}, 0,82 \mathrm{O}$ und $95,61 \mathrm{CO}^{2}$. Es wurde ferner durch Versuche festgestellt, dass das zuerst bei dem Erhitzen entweichende Gas mehr Luft sei, das später auftretende reine Kohlensäure. Um jedoch das Absorptionsverhältniss des Eisenoxydhydrates festrustellen, wurden endlich von den untersuchten Präparaten Proben über Quecksilber unter Kohlensäure gebracht. $1 \mathrm{~g}$. der Substanz nahm sehr rasch 5,5 C.C. Kohlensäure auf, welche bei dem Liegen an der Luft allmählich wieder abgegeben wurden.

Nach Gewichtsprocenten erhielt Reichardt bei den völlig reinen Präparaten 1,560 Proc. Kohlensäure, der Wassergehalt des Hydrates führte zu der Formel $2 \mathrm{Fe}^{2} \mathrm{O}^{3}+9 \mathrm{H}^{2} \mathrm{O}$; das mit $\mathrm{CO}^{2}$ gesättigte Präparat ergab 2,694 Proc. $\mathrm{CO}^{2}$; Müller fand sehr gut übereinstimmend circa 2,5 Proc.

Eine chemische Formel lässt sich dabei nicht feststellen, allein die rasche Aufnahme und Abgabe der Kohlensäure durch Eisenoxydhydrat brachte Reichardt auch zu den Versuchen, ob. nicht $\mathrm{CO}^{2}$ an Wasser abgegeben werde, um andere Stoffe zu lösen z. B. $\mathrm{CaCO}^{3}$. In der That erwiesen die Versuche, dass sich fein zertheilter, gefälter kohlensaurer Kalk beim Schütteln mit Wasser und Eisenoxydhydrat sehr wesentlich stärker löse. Während die Kalkprobe sich in 50000 Thln. kohlensäurefreiem destillirtem Wasser löst, beförderte das Eisenoxydhydrat die Lösung auf $1: 10000$.

\title{
Zur Trennung der alkalischen Erden von den Alkalien.
}

Von Dr. Emil Pfeiffer in Jena.

Die gewöhnlich für diese Trennung angewandten Methoden gehen meist darauf hinaus, Magnesia als Magnesiumoxyd und die übrigen alkalischen Erden als Carbonate zu entfernen.

Werden darauf das Filtrat und die Waschwässer verdunstet, so setzt sich, bei der nicht absoluten Unlöslichkeit 
namentlich der Carbonate, an die Wandung des dazu benutzten Platintiegels oder Schälchens regelmässig ein oft nicht unbedeutender Anflug von Erdalkalicarbonat an, den ein gewissenhafter Cheniker erst durch weitere Behandlung entfernen muss.

Man erhält aber die Alkalien stets vollkommen frei von Erdalkalien, wenn man auf folgende Weise verfuihrt:

Eine gewogene Menge der Substanz wird zur Entfernung etwaiger Ammoniaksalze gelind geglüht und darauf mit Wasser erschöpft, die wässrige Lösung aber zum Ausfällen der Magnesia mit Barythydrat oder Kalkmilch im Ceberschuss gekocht, abfiltrirt und aus dem Filtrate der Ueberschuss des Fällungsmittels, sowie etwaige, sonstige Erdalkalien durch Ammoniak und Ammoniumcarbonat kochend entfernt. Das Filtrat von diesem kochend ausgewaschenen Niederschlage wird zu einem geringen Volumen verdunstet; nach dem Erkalten mit wenig Ammoniak und einigen Kryställchen Ammoniumoxalat versetzt und $\mathrm{zu}$ einem bestimmten Volumen, beispielsweise $20 \mathrm{Cbcm}$. aufgefüllt. Nach dem Stehen über Nacht wird durch ein trocknes Filterchen in ein trockenes Glas filtrirt, wobei etwaige Verschiedenheiten von der beim Auffullen stattgehabten Temperatur durch Einsetzen in Wasser åusgeglichen werden können.

Zur Bestimmung nimmt man 5-10 oder 15 C. C. des Filtrates in Arbeit.

Nach dem Verdunsten und Glühen hinterbleiben die Alkalien gänzlich frei von Erdalkalien als kohlensaure Salze, eventuell als Chloride und es erübrigt nur noch, dieselben in die zur Gewichtsbestimmung oder Trennung geeignete Form zu bringen.

Für Ersteres empfiehlt sich die Ueberführung in Sulfate, wobei das gebildete Carbonat erst durch Ammonsulfat zersetzt wird, darauf aber das Chlorid durch Schwefelsäure in gebräuchlicher Weise.

Für die Trennung mittelst $\mathrm{Pt} \mathrm{Cl}^{4}$ genügt Verdunsten und Glühen mit Salmiak. 